\title{
Estado Moderno, Democracia e ECologia
}

\author{
Jozimar Paes de Almeida
}

Resumo: Apresento neste artigo uma abordagem sobre o surgimento da questão ecológica no seio da crise do Estado Modemo.

Unitermos: histónia contemporânea; história ambiental.

Pretendo demonstrar neste trabalho, através de um veio de raciocínio, a irrupção em um determinado momento histórico, década de 60 , a questão ecológica vinculada ao que poderíamos denominar de uma crise do Estado Moderno Democrático.

O Estado Moderno Democrático construido em fins do século XVIII e início do XIX, pelas revoluções contra a tirania se constitui em um instrumento de intervenção na sociedade, sendo efetivamente utilizado pelas classes sociais que dele se apoderam para realizar seus projetos políticos, econômicos e sociais.

Importante salientar que o Estado não pode ser compreendido simplesmente como um aparelho da classe dominante que é facilmente manipulado a seu bel-prazer, principalmente quando no seu espaço de representação política, se estabelece a democracia. Lembremo-nos de Bobbio A democracia é subversiva, portanto terreno de batalhas e conquistas das classes oprimidas.

O surgimento do Estado moderno enquanto resultante de uma luta praticada contra a aristocracia pela burguesia, que utilizou-se principalmente da democracia enquanto arma para servir seus interesses, a antiga ordem foi sacudida irreversivelmente pelo levante

Professor do Departamento de História -Universidade Estadual de Londrina Londrina/PR. 
ALMEIDA, J. P. Estado modemo, democracia e ecologia.

destruidor das camadas pobres da população, constituidas no decorrer do século XVIII, que oprimidas pela condição de miserabilidade invadem o terreno da politica, devastando-o pela violência.

A não satisfação das necessidades humanas é o motor irrefreável da ruptura do diálogo, um dos pilares constituidores da política, no entanto, os violentos tinham sido anteriormente violentados, porque foram excluídos da liberdade política por não estarem alforriados de suas atividades necessárias para a sobrevivência.

A imagem da violência não é unicamente a de uma foice ensangüentada portada por um miserável, mas é também a do governo aristocrático que levou grande massa da população à condição de penúria.

O Estado Moderno formado à partir destes enfrentamentos apresentados traz em seu cerne a questão da democracia, já que a mesma foi utilizada como instrumento de luta contra a opressão, portanto fundamento para a constituição da sociedade que emerge.

No calor das lutas sociais que se desenrolaram, as camadas pobres da população descobriram que, a democracia também é um espaço para representação de seus valores, contribuindo para tomar os oprimidos em agentes históricos, praticantes da política e libertos de suas atividades de sobrevivência.

A democracia faz com que mergulhemos nas lutas sociais, para que possamos entender e romper os grilhões da necessidade que impedem o homem de se tornar um agente histórico, e esta tarefa somente poderá ser realizada se existirem condições objetivas para a mesma, a qual ocorrerá com o surgimento da tecnologia que permitiu um grande contingente da população participar do espaço da política.

Alicerçamo-nos em Hannah Arendt:

Todo poder politico tem como fonte original e mais legítima o desejo do homem de se libertar da necessidade da vida, e os homens conseguiram essa libertação através da violencia, forçando os outros a suportar por eles o onus da vida. Isso constitui o cerne da 
ALMEIDA, J. P. Estado moderno, democracia e ecologia.

escravidão, e foi apenas o advento da tecnologia, e não o aparecimento de modernas idéias políticas, que refutou a antiga e terrivel verdade de que somente a violencia e o dominio sobre os outros podem tomar alguns homens livres. Nada, podemos hoje afirmar. pode ser mais obsoleto do que a tentativa de libertar a humanidade da pobreza por meios politicos; nada pode ser mais inutil e perigoso. Pois a violência que ocorre entre homens que se emanciparam da necessidade é menos aterrorizante, embora muitas vezes não menos cruel do que a violência primordial com que o homem se opõe à necessidade, e que apareceu pela primeira vez na idade Moderna, em plena luz de acontecimentos politicos historicamente documentados. $O$ resultado foi que a necessidade invadiu o dominio politico, o inico dominio em que os homens podem ser verdadeiramente livres.(ARENDT, 1989:90)

Toma-se obrigatório ressaltar que esta participação de grande parte da população no terreno da política se realizou nos Estados desenvolvidos tecnologicamente, enquanto ainda grande parte da humanidade, habitante de Estados não desenvolvidos, encontra-se reduzida a luta pela sobrevivência.

Essa situação é decorrente do capitalismo e de sua divisão internacional da riqueza e da produção entre Estados, produto de um processo histórico de conquista, acumulação e modemização industrial, assim também como do resultado das duas guerras mundiais que ocorreram entre os Estados Modemos.

Os Estados Modemos possuidores de colônias ou esferas de influências no restante do planeta, confrontaram-se belicamente a nivel 
ALMEIDA, J. P. Estado moderno, democracia e ecologia.

mundial por duas vezes, para destruitem seus concorrentes no mercado e ampliarem seus domínios econômico-social e político.

Rosa Luxemburgo em 1898, já havia previsto um embate militar entre as principais potências capitalistas, pela competição e identidade de seus desenvolvimentos; como também pelo militarismo: fator de defesa dos interesses nacionais na concorrência internacional, investimento para o capital financeiro e industrial e domínio sobre trabalhadores (Luxemburgo, 1986).

A produção e a riqueza contraida pelos Estados desenvolvidos, possibilitou melhorias nas condições sociais de grande parte de sua população, o problema da miséria chegou a desaparecer de seu horizonte por um curto periodo.

A participação ampliada de população no espaço da política, possibilitados por um exercício constante e uma defesa intransigente da ampliação dos direitos democráticos, deu condições a uma tomada de consciência da estrutura organizativa da sociedade. Movimentos sociais contestadores surgiram nesta sociedade, exigindo e lutando pela representação de seu valores e direitos: democracia é um espaço para a conquista de melhorias sociais.

A guerra fria, o armamentismo e a corrida nuclear propiciaram ao cidadão deste Estado Modemo, elementos para uma feroz crítica sobre o esgotamento de divisas econômicas para o setor bélico em detrimento do social. Faça amor, não faça guerra, é um lema do movimento hippie, contra-cultural que critica os valores guerreiros e consumistas do Estado Modemo.

A corrida nuclear nos remete a algo inédito na história humana e de todo o planeta: alcançamos a loucura da destruição absoluta e imediata de toda a vida, tocamos o sol e nos queimamos.

Paul Virilio, filósofo e arquiteto francês, em sua ousada análise sobre a dromologia (estudo da velocidade), nos coloca que com o advento do complexo bélico nuclear alcançamos uma nova dimensão do político - o transpolitico, que indica uma ausência de tempo para o diálogo e reflexão, caracteristica esta fundadora da própria politica (Virilio, 1984:35). 
O sistema telemático de interligação planetário das armas atômicas através de satélites, computadores e laseres, demonstra que o tempo de decisão para uma resposta a um ataque nuclear deve ser instantâneo para que seja eficaz, pois os misseis inimigos devem ser explodidos em seu silos, para não contaminarem a atmosfera terrestre com a emissão de radiações mortíferas e a destruição da camada de ozônio suporte básico para a vida na terra.

Os aspectos tecnológicos que propiciaram o imenso desenvolvimento de alguns países auxiliando o exercício da democracia, apresentam uma outra face de sua influência, quando vislumbramos a intenção apropriativa de sua utilização, a intensidade de esgotamento dos recursos energéticos e naturais e a destruição da qualidade de vida pela poluição, doenças degenerativas, contaminação de alimentos, etc.

Marshall Berman que se aventura na e pela modernidade nos esclarece que, na década de 70 , a explosão econômica e os problemas tecnológicos surgiram mais claramente:-

o grande surto econômico que
suplantara nossas expectativas por um
quarto de século após a segunda guerra
mundial estava chegando ao fim. A
combinação de inflação e estagnação
tecnológica (pela qual a ainda infindável
guerra do vietná podia ser em grande
parte responsabilizada) com uma crise
energética de caráter mundial em pleno
desenvolvimento (que em parte podiamos
atribuir a nosso sucesso espetacular)
estava fadada a cobrar tributo embora
ninguém pudesse prever no inicio da
década de 70 a dimensão de que teria
esse tributo. (Berman, 1987 : 313 ).

A crise que abala os Estados Modernos é mundial, complexa, multidimensional (tecnológica, intelectual, política, moral, econômica e 
ALMEDA, J. P. Estado moderno, democracia e ecologia.

social), minorias lutam por seus direitos (índios, negros, mulheres, homossexuais, etc.), jovens em profunda crise existencial suicidam-se.

Movimentos pacificistas, contra-culturais, ambientalistas e alternativos, procuram por vários caminhos (comunidades rurais, urbanas, alimentação natural, grupos espirituais, cooperativas de pequenos produtores) melhores soluções para seus problemas. Estrategicamente, começaram aliando-se à associações de moradores, sindicatos e partidos políticos entendendo que suas lutas são comuns e envolve não somente toda a sociedade, mas também todo o mundo.

O espaço democrático conquistado no Estado Modemo, por uma grande massa da população agora é a foz onde deságuam um manancial de contradições geradoras da sociedade moderna. Enquanto que nos paises desenvolvidos a população está hiper-alimentada jogando suas sobras literalmente para o gado, nos países não desenvolvidos morre-se de fome ao lado das plantações para a exportação. Seria cômico se não fosse trágico.

A expansão da democracia no terceiro mundo está diretamente ligada a melhoria da situação econômica de sua população oprimida que vive a beira da miséria absoluta.

A divisão da riqueza no mundo entre países e no seu interior entre as classes sociais, é resultado de um processo histórico que implantou o sistema capitalista como dominante.

A luta pela efetivação de uma democracia neste sistema é revolucionária, podendo destruí-lo completamente ao eliminar as profundas desigualdades sociais, transformando a classe oprimida em agente histórico.

Abrimos agora um espaço para que René Dumont, autor ambientalista mundialmente conhecido, possa expressar sua opinião:-

$O$ futuro do mundo permanece ligado ao progresso da democracia. Não aquela dos tribunos demagogos, que prometem dias melhores, näo aquelas dos economistas muito sábios, muito hábeis para defender em Washington os interesses dos ricos, imaginando que são o interesse do mundo. 
ALMEIDA, J. P. Estado modemo, democracia e ecologia.

Mas a dos militantes que estão
ajudando as comunidades de base $e$
agrupamentos das aldeias, as asso-
cią̧óes de párias do Sul da India, os
pobres de todos os paises'. O tempo
urge, pois outras ameaças, muito terri-
veis. estão previstas para um horizonte
bem menos longinquo do que se previa.
Além daquelas que pesam sobre todo o
ecossistema do nosso (demasiado)
pequeno planeta, com recursos tão
limitados- e tão mal dividos-, não nos
esqueçamos da ameaça da arma
atâmica.(Dumont, 1989:218)

O afloramento dos problemas ecológicos ocorre no estágio desenvolvimentista e em crise do Estado Modemo, e a resolução destes problemas estão umbilicalmente ligadas a Democracia, que para seu pleno exercício necessita de :- tempo para diálogo e reflexão, e a emancipação das necessidades básicas de sobrevivência.

\section{Referências Bibliográficas}

ARENDT, Hannah Da Revolução. (trad.) Fernando Dídimo Vieira. São Paulo: UNB/Ática, 1988.

BERMAN, Marshall Tudo que é Sólido Desmancha no Ar. São Paulo: Cia das Letras, 1987.

DUMONT, René Um Mundo Intoleráve. (trad.) Edison Darci Heldt. Rio de Janeiro: Ed. Revan, 1989.

LUXEMBURGO, Rosa Reforma Social ou Revoluçäo?. São Paulo: Ed. Global, 1986.

VIRILIO, Paul e LOTRINGER, Sylvére Guerra Pura. (trad.) Elza Miné e Laymert Garcia dos Santos. São Paulo: Brasiliense, 1984. 